\title{
Reducing Dephosphorization of SiMn Alloy Melt and Suppression of Phosphine $\left(\mathrm{PH}_{3}\right)$ Gas Emission
}

\author{
Jae-Hong Shin, Joo Hyun Park* \\ Department of Materials Engineering, Hanyang University \\ Ansan 426-791, Korea \\ *basicity@ hanyang.ac.kr
}

\begin{abstract}
The dephosphorization (de-P) efficiency of $\mathrm{SiMn}$ alloy melt using $\mathrm{CaO}-\mathrm{CaF}_{2}$ flux was measured at $1823 \mathrm{~K}$ under a strongly reducing atmosphere. De-P efficiency increased by increasing the $\mathrm{CaO}$ content up to $\mathrm{CaO}$ saturation point in the $\mathrm{CaO}-\mathrm{CaF}_{2}$ flux at 1823 $\mathrm{K}$, indicating that the phosphorus was removed from the SiMn melt by the reducing refining mechanism. When the Vee ratio (= $\mathrm{CaO} / \mathrm{SiO}_{2}$ ) of the reducing de-P slags is greater than about 1.35, the lime and dicalcium silicate phases precipitated during solidification, resulting in an increase in the emission rate of $\mathrm{PH}_{3}$ gas due to an increase in the reaction area. However, when the Vee ratio of the slags is lower than about 1.35, the fluorite, cristobalite, and wollastonite phases appeared from the phase diagram, resulting in less amount of $\mathrm{PH}_{3}$ emission during cooling because the reaction between $\mathrm{Ca}_{3} \mathrm{P}_{2}$ and $\mathrm{H}_{2} \mathrm{O}$ was restricted to the surface of bulk slag.
\end{abstract}

Keywords: Reducing dephosphorization, $\mathrm{SiMn}$ alloy, $\mathrm{CaO}-\mathrm{CaF}_{2}$ flux, Vee ratio, Dicalcium silicate, Phosphine $\left(\mathrm{PH}_{3}\right) \mathrm{gas}$

\section{Introduction}

High manganese steels are of interest due to their good mechanical properties including superior strength and good ductility [1]. Accordingly, the demand for ultra-low phosphorus manganese alloys such as FeMn and SiMn alloys has recently increased. However, the conventional oxidizing dephosphorization (de-P) technique is not applicable to manganese alloys because silicon or manganese will be oxidized before phosphorus under oxidizing conditions [2]. Therefore, the de-P should be carried out under a strongly reducing atmosphere based on Eq. (1) to produce a low phosphorus Si-Mn alloy [3]. However, because the calcium phosphide $\left(\mathrm{Ca}_{3} \mathrm{P}_{2}\right)$, which is a reaction product of the reducing de-P mechanism, is very active when it is exposured to moisture, the hazardous phosphine gas $\left(\mathrm{PH}_{3}\right)$ evolves as given in Eq. $(2)[2,3]$.

$$
\begin{gathered}
{[\mathrm{P}]_{\mathrm{SiMn}}+3 / 2\left(\mathrm{O}^{2-}\right)=\left(\mathrm{P}^{3-}\right)+3 / 4 \mathrm{O}_{2}(\mathrm{~g})} \\
{[\mathrm{P}]_{\mathrm{SiMn}}+3 / 2(\mathrm{CaO})=1 / 2\left(\mathrm{Ca}_{3} \mathrm{P}_{2}\right)+3 / 4 \mathrm{O}_{2}(\mathrm{~g})} \\
\mathrm{Ca}_{3} \mathrm{P}_{2}(\mathrm{~s})+3 \mathrm{H}_{2} \mathrm{O}(\mathrm{g})=3 \mathrm{CaO}(\mathrm{s})+2 \mathrm{PH}_{3}(\mathrm{~g}) \\
\mathrm{Ca}_{3} \mathrm{P}_{2}(\mathrm{~s})+6 \mathrm{H}_{2} \mathrm{O}(\mathrm{g})=3 \mathrm{Ca}(\mathrm{OH})_{2}(\mathrm{~s})+2 \mathrm{PH}_{3}(\mathrm{~g})
\end{gathered}
$$

Thus, it is inevitable to evolve the $\mathrm{PH}_{3}$ gas during cooling of slags containing $\mathrm{Ca}_{3} \mathrm{P}_{2}$ under moist atmosphere. Phosphine gas is hazardous to environment as well as to human being. Severe phosphine poisoning can cause convulsions, damage to the lungs, heart, liver and kidney, and death [4]. Therefore, this study consists of the distribution behaviour of phosphorous between the $\mathrm{CaO}-\mathrm{CaF}_{2}\left(-\mathrm{SiO}_{2}\right)$ flux and $\mathrm{SiMn}$ alloy melt at $1823 \mathrm{~K}$, and includes the thermodynamic and kinetics analyses for the environmental stability of reducing de-P slags under wet and dry cooling conditions based on the effect of slag composition on the evolution of $\mathrm{PH}_{3}$ gas.

\section{Experimental Procedure}

A super-kanthal electric furnace was used for the equilibration of the $\mathrm{CaO}-\mathrm{CaF}_{2}$ flux and $\mathrm{Si}-\mathrm{Mn}$ alloy melts. The temperature was controlled within $\pm 2 \mathrm{~K}$ using a B-type thermocouple and a PID controller. The slag samples were prepared using reagent grade $\mathrm{CaF}_{2}$ and $\mathrm{CaO}$ calcined from $\mathrm{CaCO}_{3}$ at $1273 \mathrm{~K}$ for 10 hours. The experimental composition of the slag in the $\mathrm{CaO}-\mathrm{CaF}_{2}$ system ranged from 5 to $25 \% \mathrm{CaO}$. The schematic diagram of the experimental apparatus is shown in previous articles $[3,5,6]$. The slag and SiMn alloy were held in graphite crucibles under a $\mathrm{CO}$ atmosphere to equilibrate. For 
reducing removal of phosphorus under a very low oxygen potential, $\mathrm{CO}$ gas was diluted with Ar. With a $\mathrm{CO} /(\mathrm{CO}+\mathrm{Ar}) \mathrm{ratio}$ of 0.25 , the oxygen partial pressure is about $1.83 \times 10^{-17}$ atm at $1823 \mathrm{~K}$.

The samples were quenched by dipping half of the crucible into brine and the samples were then crushed for chemical analysis. Furthermore, after equilibrating for 12 hours, some of the slag samples were cooled under fully moisturized condition (direct contact with water spray), whereas the other samples were quickly quenched from $1823 \mathrm{~K}$. Then, the samples were rapidly crushed for chemical analysis under inert atmosphere. The composition of metal samples were determined using ICP-AES and the equilibrium composition of slag was determined using XRF spectroscopy. The crystalline phases of solidified slags were identified using XRD analysis.

\section{Results and Discussion}

In the present study, the de-P efficiency $\left(\eta_{\mathrm{de}-\mathrm{P}}, \%\right)$ was determined from the following equation:

$$
\eta_{\mathrm{de}-\mathrm{P}}(\%)=\left([\% \mathrm{P}]^{\mathrm{o}}-[\% \mathrm{P}]^{\mathrm{e}}\right) /[\% \mathrm{P}]^{\mathrm{o}} \times 100
$$

where the superscripts ' $\mathrm{o}$ ' and ' $\mathrm{e}$ ' represent the initial and the equilibrium content of phosphorus in the metal, respectively. The effect of the $\mathrm{CaO}$ content in the $\mathrm{CaO}-\mathrm{CaF}_{2}$ flux on the de-P efficiency of the SiMn alloy at $1823 \mathrm{~K}$ is shown in Figure 1(a). The de-P efficiency increases with increasing $\mathrm{CaO}$ content up to $20 \%$, which is due to the increase in the basicity of the flux. This means that the reducing refining mechanism was confirmed through the transfer of Ca from the slag to the metal phase due to the reaction between $\mathrm{CaO}$ in the flux and $\mathrm{Si}$ in the alloy under strongly reducing conditions (Eqs. (4) and (5)).

$$
\begin{gathered}
2(\mathrm{CaO})+[\mathrm{Si}]_{\mathrm{SiMn}}=\left(\mathrm{SiO}_{2}\right)+2[\mathrm{Ca}]_{\mathrm{SiMn}} \\
3[\mathrm{Ca}]_{\mathrm{SiMn}}+2[\mathrm{P}]_{\mathrm{SiMn}}=\left(\mathrm{Ca}_{3} \mathrm{P}_{2}\right)
\end{gathered}
$$

However, the de-P efficiency remained constant at $\mathrm{CaO}$ contents greater than about $20 \%$, where the flux is saturated by solid lime from the $\mathrm{CaO}-\mathrm{CaF}_{2}$ binary phase diagram [7]. The effect of $\mathrm{CaO}$ content on the amount of phosphine gas evolved which was normalized with reference to the dry-quenched samples is shown in Figure 1(b). In the lower CaO content region, viz. $a_{\mathrm{CaO}}<1.0$, the phosphine gas was evolved due to the large potential of $\mathrm{H}_{2} \mathrm{O}$ which is greater than that of $\mathrm{CaO}$. However, even in the higher $\mathrm{CaO}$ content region, viz. $a_{\mathrm{CaO}}=1.0$, the phosphine gas is still evolved, which is contradictory to the thermodynamic expectation.

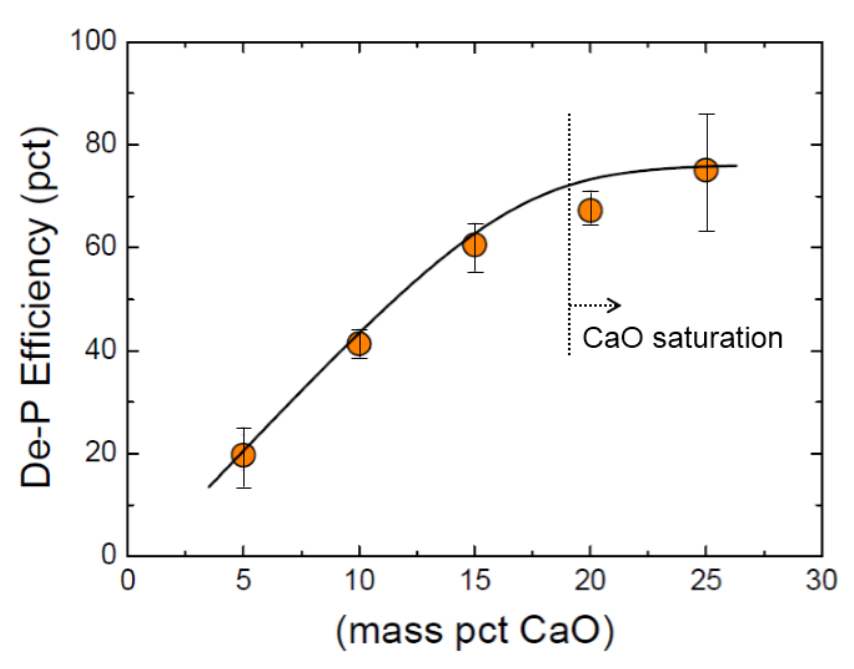

(a)

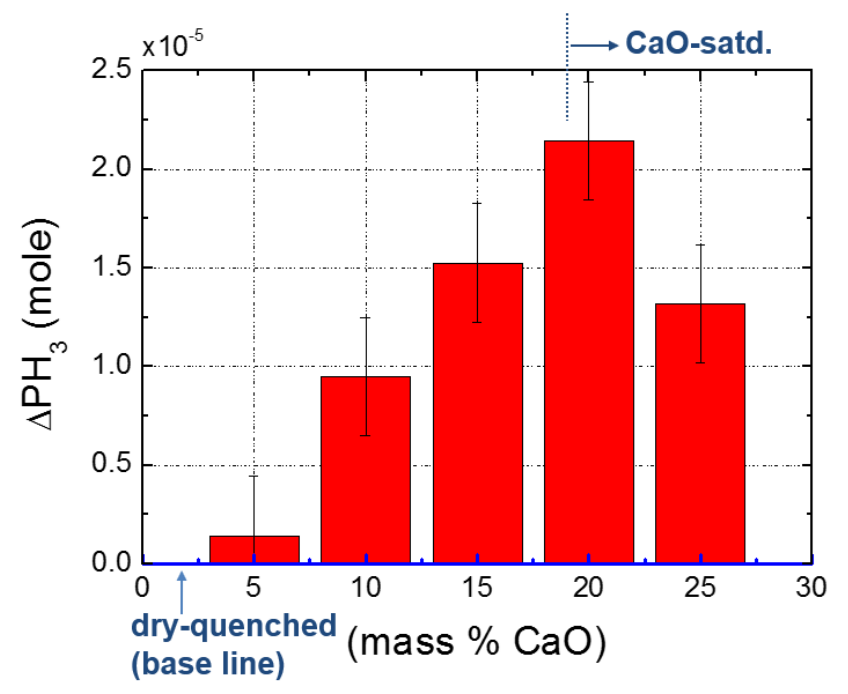

(b)

Fig. 1. Effect of $\mathrm{CaO}$ content on (a) the de-P efficiency of the $\mathrm{CaO}-\mathrm{CaF}_{2}$ flux and (b) on the evolution of $\mathrm{PH}_{3}$ gas. 
When the $\mathrm{CaO}$ content is greater than about $15 \%$, the slag was disintegrated into fine powders during cooling. The powdery slag in the $\mathrm{CaO}-\mathrm{CaF}_{2}-\mathrm{SiO}_{2}$ slag is formed by two factors. Firstly, if $\mathrm{CaO}$ (lime) is crystallized during solidification under wet conditions, the hydration of $\mathrm{CaO}$ occurs, resulting in the volume expansion of slag. $\mathrm{Secondly}_{2}$ if $\mathrm{Ca}_{2} \mathrm{SiO}_{4}$ (dicalcium silicate) is crystallized during solidification, the $\mathrm{Ca}_{2} \mathrm{SiO}_{4}$ also contributes to powdery slag because of the volume expansion by the phase transformation of $\mathrm{Ca}_{2} \mathrm{SiO}_{4}$ from $\beta$ - to $\gamma$-phase at about $773 \mathrm{~K}$ [8]. Here, the content of $\mathrm{SiO}_{2}$ increased due to slag-metal reaction which is given in Eq. (4). The more the slags become powdery, the larger the reaction surface area is expected, and thus the rate of gas evolution increases as a quadratic function. Therefore, if $\mathrm{CaO}$ or $\mathrm{Ca}_{2} \mathrm{SiO}_{4}$ are precipitated during solidification even in highly dry atmosphere, the evolution of $\mathrm{PH}_{3}$ gas could not be negligible.

The slag composition after de-P is plotted on the $\mathrm{CaO}-\mathrm{CaF}_{2}-\mathrm{SiO}_{2}$ ternary phase diagram as shown in Figure 2 [9]. Solidification path can be predicted based on polythermal projection of the $\mathrm{CaO}-\mathrm{CaF}_{2}-\mathrm{SiO}_{2}$ ternary phase diagram. Figure 3 shows the schematic diagram of cooling path and the microstructure of solidified slag in each case ' $a$ ' and 'b' in Figure 2. For slags \#1 and \#2, the $\mathrm{CaF}_{2}$ is primarily crystallized, followed by the nucleation and growth of $\mathrm{SiO}_{2}$ (cristobalite). Finally the slag solidifies at the $\mathrm{CaF}_{2}-\mathrm{SiO}_{2}-\mathrm{CaSiO}_{3}$ ternary eutectic composition. That is, the rate of phosphine gas evolution is relatively low, because the solid compounds that contribute to the disintegration are not precipitated.

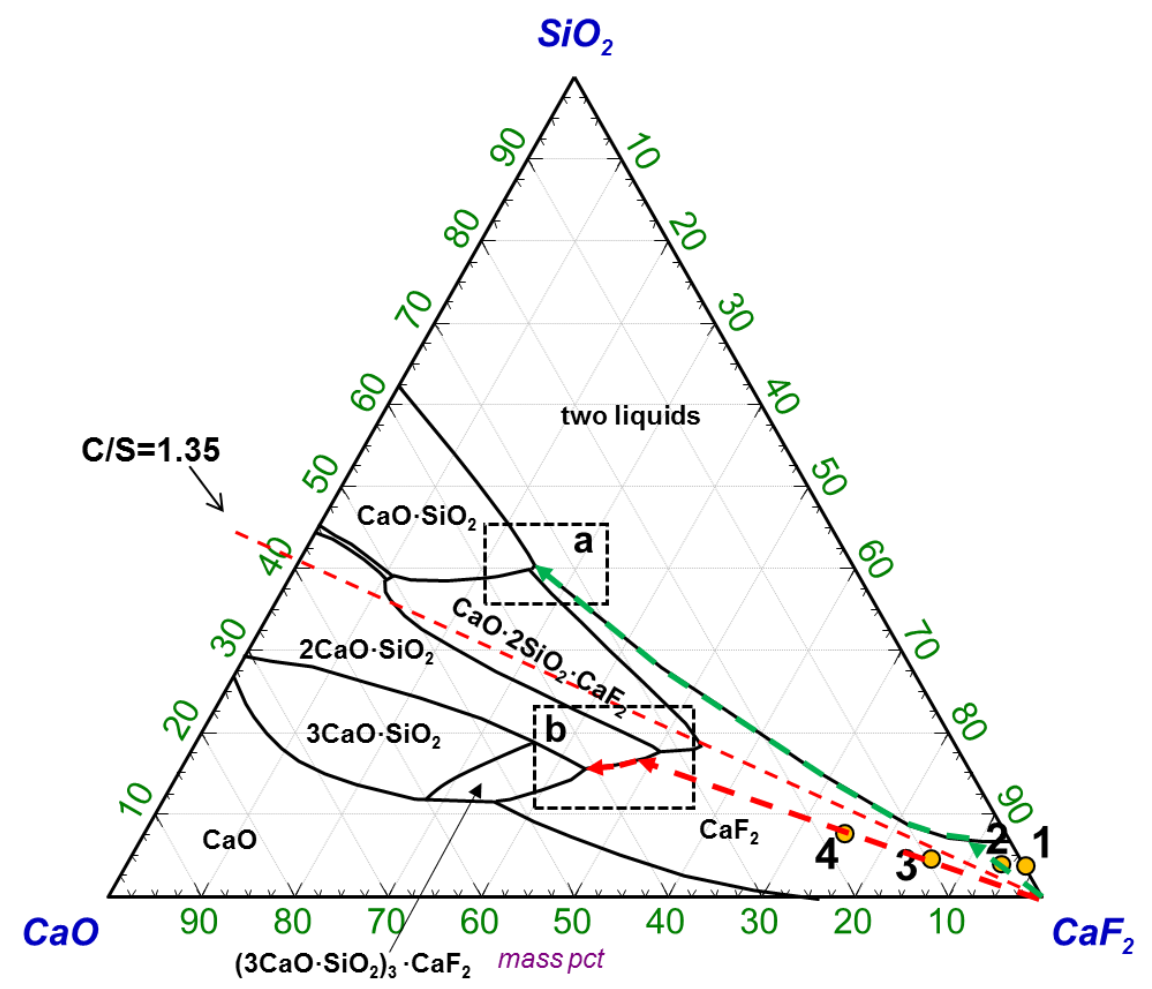

Fig. 2. Slag composition after de-P reaction plotted on the $\mathrm{CaO}-\mathrm{CaF}_{2}-\mathrm{SiO}_{2}$ ternary phase diagram.

On the other hand, for slags \#3 and \#4, the $\mathrm{CaF}_{2}$ is primarily crystallized, followed by the nucleation and growth of $\mathrm{Ca}_{2} \mathrm{SiO}_{4}$. After that, slag solidifies at the $\mathrm{CaF}_{2}-\mathrm{Ca}_{2} \mathrm{SiO}_{4}-\left(3 \mathrm{CaO} \cdot \mathrm{SiO}_{2}\right)_{3} \mathrm{CaF}_{2}$ ternary eutectic composition. That is, the rate of phosphine gas emission is relatively high, because the solid compound which contributes to the disintegration of slag, e.g. $\mathrm{Ca}_{2} \mathrm{SiO}_{4}$ is precipitated.

Consequently, when the Vee ratio $\left(=\mathrm{CaO} / \mathrm{SiO}_{2}\right)$ of the de-P slag is greater than about 1.35 , the $\mathrm{CaO}$ (lime) and $\mathrm{Ca}_{2} \mathrm{SiO}_{4}$ (dicalcium silicate) phases precipitated during cooling cycle. This can be a reason for a decrease in between dry-quenched and wet-cooled $25 \% \mathrm{CaO}$ samples in Figure 1(b). That is, even it was directly quenched under dry atmosphere, the slag was disintegrated into fine powders, resulting in an emission of $\mathrm{PH}_{3}$ gas before chemical analysis. Therefore, there was less difference in between dry-quenched and wet-cooled slag samples in highly basic compositions. Therefore, it is strongly recommended that reducing de-P slags should be kept or treated under dry atmosphere. Furthermore, the Vee ratio of de-P slag should be controlled to be lower than 1.35 during reducing refining process. 

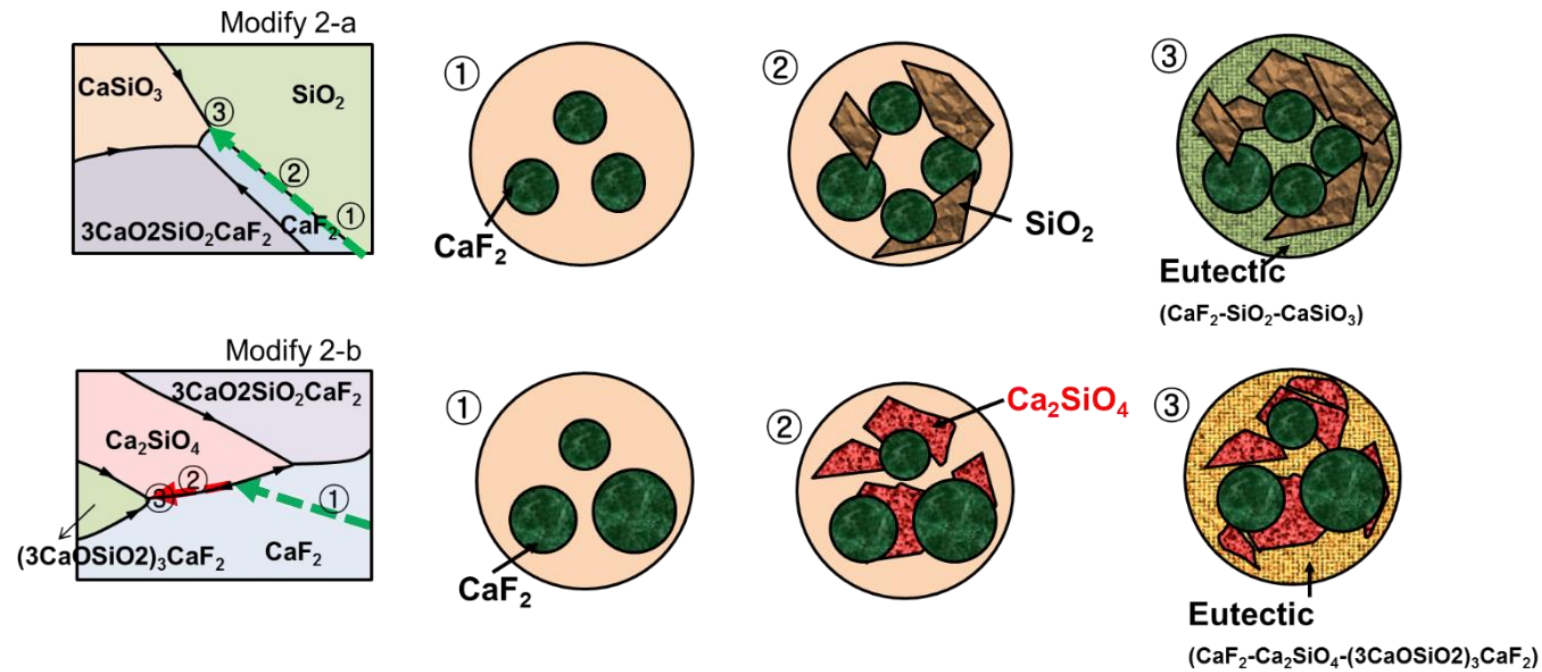

Fig. 3. Schematic diagram of cooling path and solidification structure of de-P slags.

\section{Conclusions}

In the present study, the de-P efficiency $\left(\eta_{\mathrm{de}-\mathrm{P}}, \%\right.$ ) of $\mathrm{SiMn}$ alloy melt using $\mathrm{CaO}-\mathrm{CaF}_{2}$ flux was determined at 1823 $\mathrm{K}$ under a strongly reducing atmosphere. It increased with increasing $\mathrm{CaO}$ concentration in the flux up to a point before reaching a constant value. The composition for the saturating value is in good agreement with the saturation content of $\mathrm{CaO}$ in the $\mathrm{CaO}-\mathrm{CaF}_{2}$ flux at $1823 \mathrm{~K}$, indicating that the phosphorus was removed from the $\mathrm{SiMn}$ melt by the reducing refining mechanism. When the Vee ratio $\left(=\mathrm{CaO} / \mathrm{SiO}_{2}\right)$ of the reducing de-P slags is greater than about 1.35 , the lime and dicalcium silicate phases precipitated during solidification, resulting in an increase in the emission rate of $\mathrm{PH}_{3}$ gas due to an increase in the reaction area. However, when the Vee ratio of the slags is lower than about 1.35, the fluorite, cristobalite, and wollastonite phases appeared from the phase diagram, resulting in less amount of $\mathrm{PH}_{3}$ emission during cooling because the reaction between $\mathrm{Ca}_{3} \mathrm{P}_{2}$ and $\mathrm{H}_{2} \mathrm{O}$ was restricted to the surface of bulk slag.

\section{References}

[1] K. H. So, J. S. Kim, Y. S. Chun, K. T. Park, Y. K. Lee, and C. S. Lee, "Hydrogen Delayed Fracture Properties and Internal Hydrogen Behaviour of a Fe-18Mn-1.5Al-0.6C TWIP Steel,” ISIJ Int., vol. 49, pp. 1952-1959, 2009.

[2] S. Tabuchi and N. Sano, "Thermodynamics of Phosphate and Phosphide in $\mathrm{CaO}-\mathrm{CaF}_{2}$ Melts," Metall. Trans. B, vol. 15B, pp. 351-356, 1984.

[3] J. H. Shin and J. H. Park, "Thermodynamics of Reducing of Phosphorus from Si-Mn Alloy Using $\mathrm{CaO}_{-\mathrm{CaF}} \mathrm{Slag}$," Metall. Mater. Trans. B, vol. 43B, pp. 1243-1246, 2012.

[4] J. L. Burgess, "Phosphine Exposure from a Methamphetamine Laboratory Investigation," J. Toxicology - Clinical Toxicology, vol. 39, pp. 165-168, 2001.

[5] J. H. Shin and J. H. Park, "Effect of Atmosphere and Slag Composition on the Evolution of $\mathrm{PH}_{3}$ Gas during Cooling of Reducing Dephosphorization Slags," ISIJ Int., vol. 53, pp. 385-390, 2013.

[6] J. H. Shin and J. H. Park, "Conversion of Calcium Phosphide to Calcium Phosphate in Reducing Dephosphorization Slags by Oxygen Injection," ISIJ Int., vol. 53, pp. 2266-2268, 2013.

[7] W. G. Seo, D. Zhou, and F. Tsukihashi, "Calculation of Thermodynamic Properties and Phase Diagrams for the CaO$\mathrm{CaF}_{2}, \mathrm{BaO}-\mathrm{CaO}$ and $\mathrm{BaO}-\mathrm{CaF}_{2}$ Systems by Molecular Dynamics Simulation," Mater. Trans., vol. 46, pp. 643-650, 2005.

[8] D. Min, H. Dongwen, L. Xianghui, and T. Mingshu, "Mechanism of Expansion in Hardened Cement Pastes with HardBurnt Free Lime," Cement Concrete Res., vol. 25, pp. 440-448, 1995.

[9] T. Watanabe, H. Fukuyama, and K. Nagata, "Stability of Cuspidine $\left(3 \mathrm{CaO}_{2} \cdot \mathrm{SiO}_{2} \cdot \mathrm{CaF}_{2}\right)$ and Phase Relations in CaO$\mathrm{SiO}_{2}-\mathrm{CaF}_{2}$ System," ISIJ Int., vol. 42, pp. 489-497, 2002. 